\begin{tabular}{|c|c|c|}
\hline $\begin{array}{l}\text { An International Biannual Open Access } \\
\text { Peer-Reviewed/Refereed Journal } \\
\text { JOURNAL OF GLOBAL RESOURCES } \\
\text { Published by : ISDESR, Jaipur, India }\end{array}$ & 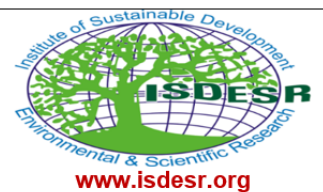 & $\begin{array}{r}\text { ISSN: } 2395-3160 \text { (Print) } \\
\text { ISSN: } 2455-2445 \text { (Online) } \\
\text { January 2022, Volume } 08(01) \\
\text { DOI Prefix: } 10.46587 / J G R\end{array}$ \\
\hline
\end{tabular}

01

\title{
ANALYSIS OF GREEN CAMPUS POTENTIAL IN PARTS OF ARID ZONE USING HYDRO-LANDSCAPE TECHNIQUE
}

\author{
Monika, ${ }^{1}$ Amina Zakiah ${ }^{2}$ and Gauhar Mahmood ${ }^{3}$ \\ ${ }^{1}$ Assistant Professor, Chandigarh College of Architecture, Chandigarh, India \\ ${ }^{2}$ Environmental Consultants Aqua Explorers, Delhi, India \\ ${ }^{3}$ Professor, Jamia Millia Islamia University, New Delhi, India \\ Email: aminazakiah23@gmail.com
}

How to cite this paper:

Monika; Zakiah, Amina and

Mahmood, Gauhar (2022)

Analysis of green campus potential in parts of arid zone using hydro-landscape technique, Journal of Global Resources, Vol. 08 (01)

DOI:

10.46587/JGR.2022.v08i01.001

Received: 07 Nov. 2021

Reviewed: 18 Nov. 2021

Revised: 27 Nov. 2021

Final Accepted: 02 Dec. 2021

OPEN O ACCESS

Freely available Online

www.isdesr.org
Abstract: India is a massive country with wide range of climatic condition in terms of rainfall, temperature, depth of ground water level, soil cover etc. These variations may affect the ground cover such as in Tropical and sub-tropical zone the scarcity of rainfall and the micro-climate becomes conducive for the growth of vegetation where as in arid zone such as Gujarat and Rajasthan- the soil and water are not very favorable, as a consequence scarcity of vegetation. The current view on climatic analysis of India clearly indicates that the development of Green Campus in arid climate zone will be a challenging issue especially in the field of landscape architecture. The basic issues related to arid climate is depletion in the depth of ground water level condition by virtue of which the vegetation in general is decreasing. In this way, the hydro-landscape technique will be useful for Green Campus development in part of arid zone with selective areas conducive to develop of soil moisture content. The present study is with the application of hydro-landscape technique to develop the green campus in arid climate in order to establish the area with conducive environment.

Key words: Hydro-Landscape, Micro-Climate, Arid Zone, Green Campus. 


\section{Introduction}

India is a naturally vast country with lots of variation in climatic condition where the rainfall varied from $100 \mathrm{~mm}$ per year in the extreme arid climate like Jaisalmer and $11000 \mathrm{~mm}$ per year in the extreme tropical climate like Dehradun, Meghalaya. There is a variety of soil as ground cover is available where the pure sandy soil with sand dunes characterization is encountered in the extreme arid climate. Similarly, the muddy and clayey soil with very thin cover is available in the Meghalaya region where most of the areas are exposed with rock out crop. Due to a great variation in rainfall and the soil cover, vegetation cover varied accordingly. Most of the climatic condition in India like Tropical and sub-tropical zone where the scarcity of rainfall and the microclimate becomes conducive for the growth of vegetation. As a result, the tropical and sub-tropical area in India is not facing much problem for the establishment of Green Campus. However, the other side of the climatic condition of India i.e. semi-arid to arid region are facing difficult and complex issues pertaining to development of Green Campus. The semi-arid climate where ever have got the conducive environment like water and soil with comparatively good character develop the vegetation. The most challenging part in India for the development of Green Campus in arid climate especially, the part of Gujarat and Rajasthan where soil and water are not very conducive, as a result vegetation suffers. The above-mentioned climatic analysis of India clearly shows that the development of Green Campus in arid climate zone will be a challenging issue especially in the field of landscape architecture.

The basic issues related to arid climate is variation in water level condition which is going down day by day and has required the declining trend by virtue of which the vegetation in general is decreasing. All these are related to climate change and pressure on the temperature condition where the temperature is increasing and rate of evaporation and transpiration is also increasing. As a result, most of the plant species do not get the requisite amount of soil moisture and therefore, the roots of the vegetation do not give the proper energy and food. Therefore, most of the vegetation are losing its chlorophyll value and canopy, its density and pattern. In order to establish the relationship among soil, water and vegetation, water plays an important role and it is the only variable factor which could be decreased or increased depending upon the feasibility and designing of Green Campus because soil is a constant parameter which doesn't change. It is being in general in arid climate whenever the hydro-physiographic units are conducive in nature, which results the positive growth in Green Campus. For example, within arid zone area, a gradation zone is occupied by the sand and dunes where the vegetation is almost nil. In the gradation, if the area is closer to water body in that case the possibility of vegetation is there. However, if the gradation zone is away from water body, then the vegetation growth has been affected and very less vegetative growth is possible. Most of the vegetation are grown in the gradation part of arid zone where the possibility of the water body during the rainy season are encountered and in the dry season, some of the vegetation sustained due to soil moisture content. The above analysis clearly indicates the possibility of the Green Campus within arid zone wherever the area has drought comparatively good soil moisture content with the help of hydrolandscape technique.

\section{Objective}

The following are the objectives of study:

1. To delineate the arid climate zone in parts of Rajasthan and Gujarat as study area.

2. To assess the climatic factor such as rainfall, temperature and humidity.

3. To delineate the soil map for the area.

4. To delineate the hydrological map of the study area. (depth of water level map for premonsoon and post monsoon along the fluctuation map.)

Finally, to develop for Green Campuses within the arid region in parts of Rajasthan and Gujarat using hydro-landscape technique.

\section{Scope of the Study}

Due to climate change and increase in temperature, the green vegetation is suffering in parts of arid climatic zone especially in Rajasthan and Gujarat. Besides, the urbanization and tourism are also playing a negative role to the natural green vegetation cover. The present study will provide an idea for development of Green Campus in parts of Rajasthan and Gujarat in arid climate zone 
using hydro-landscape technique. So far, no extensive research has been done in this area to establish the relationship among soil, water and vegetation. Because in our country, all these three subjects have been done in isolation. This study is the amalgamation of all three organizational research in one platform as the hydro-landscape require the advance research methodologies used by soil organization, water resource organization as well as the horticulture department.

\section{Research Methodology}

The following consideration has been undertaken in order to fulfill the scope and objective of the study for the development of Green Campus in the study area using hydro-landscape techniques. The climate map of India was taken as reference point in order to delineate the arid climate in the study area for which a map has been prepared for the location of the study area to super impose the various required issues pertaining to development of Green Campus using hydro-landscape technique (Fig. 1).

Figure 01: Arid zone map, Source: www.mapsofindia.com

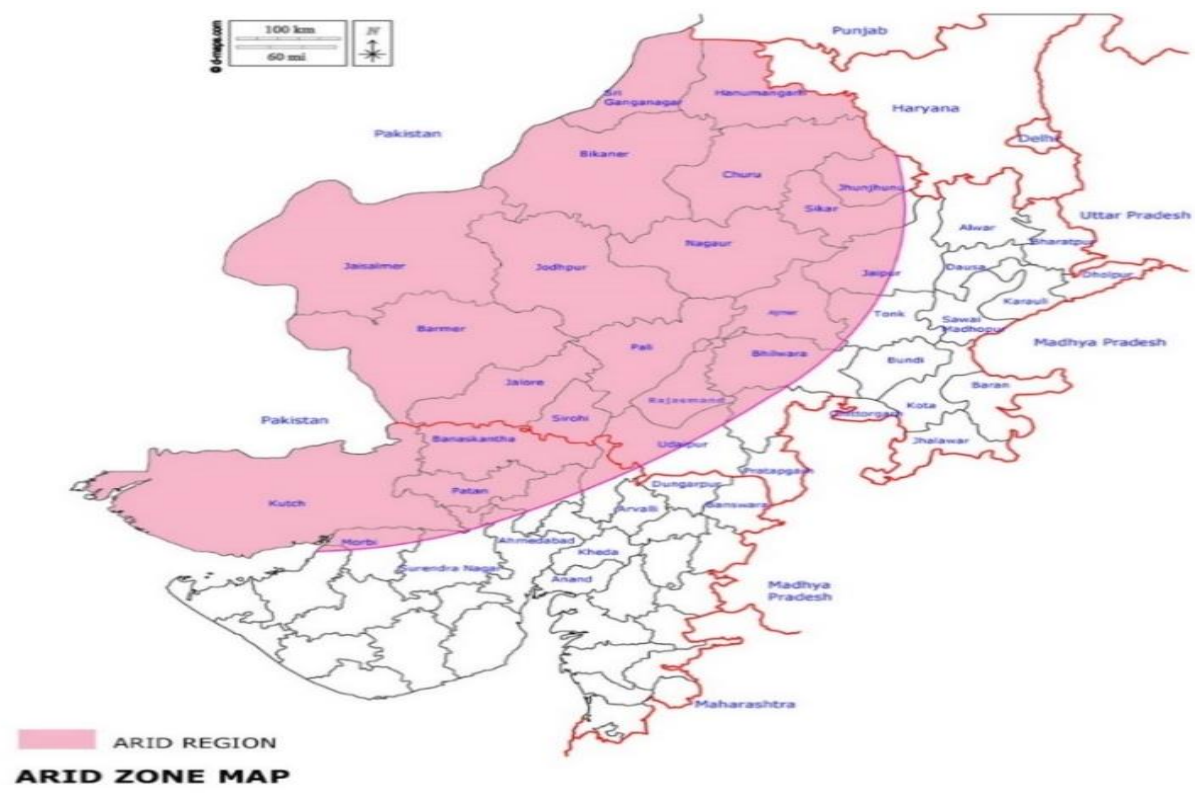

The study area was referred to rainfall map of India sighted by India Meteorological Department and other literatures like book of Hydrology by Prof. K. Subramanya for the preparation of the Iso-hytal map for the depiction of rainfall. The temperature map was prepared using Iso-thermic analysis for the study area and Iso-thermic zoning has been done for the assessment of temperature in the study area using India Meteorological Department data. Similarly, humidity map was prepared using IMD Department. Soil map of the study area of Rajasthan and Gujarat arid zone were prepared from Agricultural department. Hydro map was prepared by CGWB for the year 2019-2020. Based on that the following maps are prepared (refer CGWB 2019-2020 Report of Gujarat and Rajasthan):

1. Ground water level fluctuation

2. Annual water level fluctuation

3. Decadal water level fluctuation average

\section{ANALYSIS AND DISCUSSION Delineation of Arid Zone}

As per our research theme for the development of Green Campus, the main objective with a complex situation falls under arid zone because of the parameters such as rainfall, temperature, evaporation, evapo-transpiration, water level condition and water body with precise relation among soil, water and vegetation. Since the tropical zone falls under high rainfall condition with good variety of soil and rock coverage. Therefore, the vegetation cover has brought the enormous potential in the tropical zone where the natural green coverage has got the sufficient amount of area. Hence, the development of green campus in this area doesn't require the recognized efforts. 
The sub-tropical zone has also good potential of rainfall, temperature, humidity, evaporation and evapo-transpiration with good potential of water level condition. Therefore, the sub-tropical zone like the tropical zone has got the good natural potential of green campus. The semi-arid zone has got the low medium potential for the development of the green campus especially in the urban area where the built-up zone is increasing gradually overwhelmed with the latest state of hour. The semi-arid zone can be developed for the green campus in point of view if the water management is taken care with the use of all variety of water like rainwater, treated waste water, flood water, water from the water-logged area. The most challenging job for the development of the green campus in arid zone on account of low rainfall, high temperature climate, high evaporation rate and deep-water level condition along with occasional water bodies will be challenging job. The delineation of the arid zone has been classified on the basis of low rainfall, high temperature, sandy soil, dry vegetation covers as well as low potential of water bodies and deep-water level condition. The arid zone falls mostly in Rajasthan and partly it covers Gujarat as per delineation of the map. (Fig. 1)

\section{ASSESSMENT OF CLIMATIC FACTOR: RAINFALL, TEMPERATURE AND HUMIDITY}

The assessment of the climatic factor such as rainfall, temperature, evaporation and evapotranspiration along with the depth to water level and water level fluctuation which may be discuss as follows:

\section{Analysis of rainfall condition and behavior in arid zone area}

The average annual rainfall has been considered on the basis of data taken from the IMD sources. The average annual rainfall of the study area varies from $100 \mathrm{~mm}$ to $1000 \mathrm{~mm}$ (Fig.2).

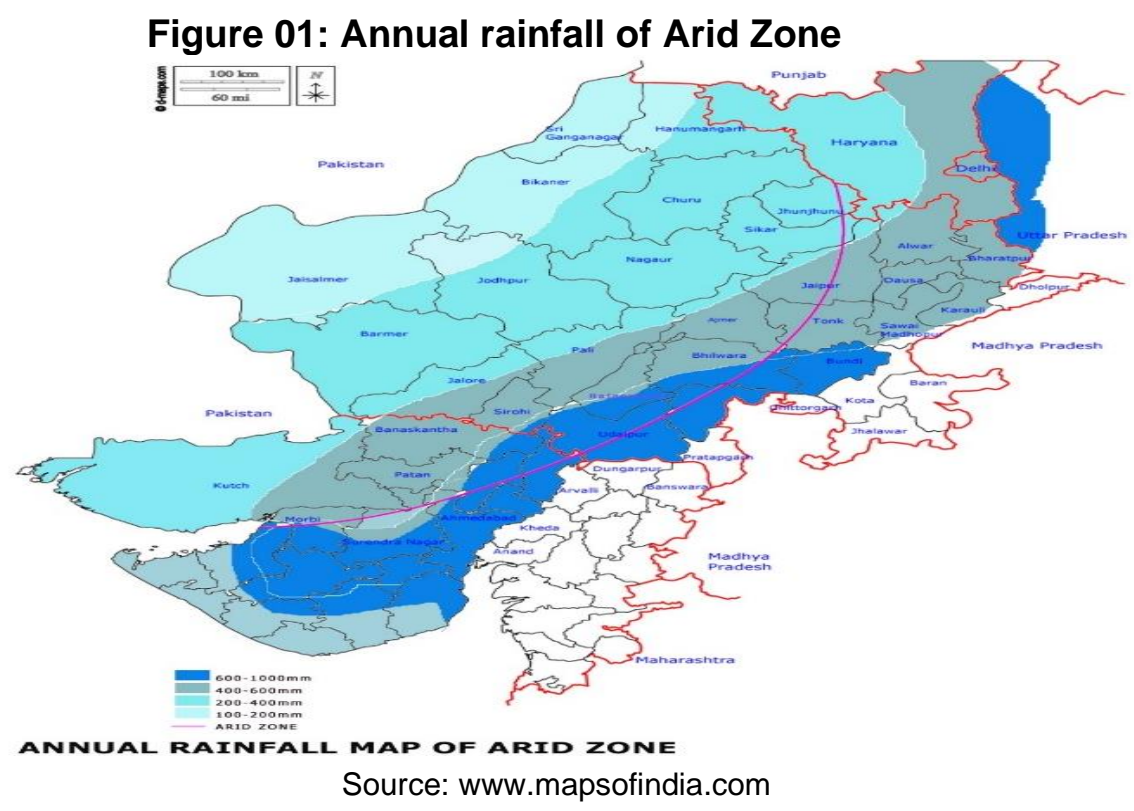

The area has been classified further in four annual average rainfall zone which may be described as follow:

Table 01: Analysis of Annual Average Rainfall Condition

\begin{tabular}{|l|l|c|c|}
\hline $\begin{array}{l}\text { Annual average } \\
\text { rainfall }(\mathrm{mm})\end{array}$ & Area of arid zone & $\begin{array}{l}\text { Covers in percent } \\
\text { of the total arid zone }\end{array}$ & $\begin{array}{l}\text { Covered area } \\
\text { (sq.km.) }\end{array}$ \\
\hline $600-1000$ & Udaipur, Rajasmand, Bhilwara & 5.5 & 17597.34 \\
\hline $400-600$ & $\begin{array}{l}\text { Patan, Bnaskantha, Sirohi, Jaipur, } \\
\text { Tonk etc. }\end{array}$ & 21.21 & 67855.67 \\
\hline $200-400$ & $\begin{array}{l}\text { Barmer, Nagaur, Sikar, Jhujhunu, } \\
\text { Churu }\end{array}$ & 50.05 & 160100.32 \\
\hline $100-200$ & $\begin{array}{l}\text { Jaisalmer, Sri GangaNagar, } \\
\text { Bikaner }\end{array}$ & 23.22 & 74263.65 \\
\hline
\end{tabular}

On the basis of analysis of annual average rainfall condition, it is found that the area falls under $600-1000 \mathrm{~mm}$ annual average rainfall will have the highest potential zone for the development of green campus. The analysis of the map further indicates the location of the 
highest potential zone for the development of the green campus subject to the condition of urbanization and tourism potential etc. The annual average rainfall ranges from $200 \mathrm{~mm}-400 \mathrm{~mm}$ comprises the largest area in the arid zone as compared to the other areas and will have the challenging task for the development of the green campus subject to the urbanization and tourism potential. Whereas the annual average rainfall $100-200 \mathrm{~mm}$ ranges will be high complex situation for the development of the green campus.

\section{Iso-thermic analysis of arid zone:}

The Iso-thermic analysis indicates variation available in the study area of arid zone. Maximum and minimum annual temperature on the basis of IMD data was prepared with classification of four zone as shown (Fig.3 and 4). The average annual maximum temperature has been taken from pre-monsoon (June) whereas the annual minimum temperature from January.

\section{Figure 03: Maximum temperature of arid zone}

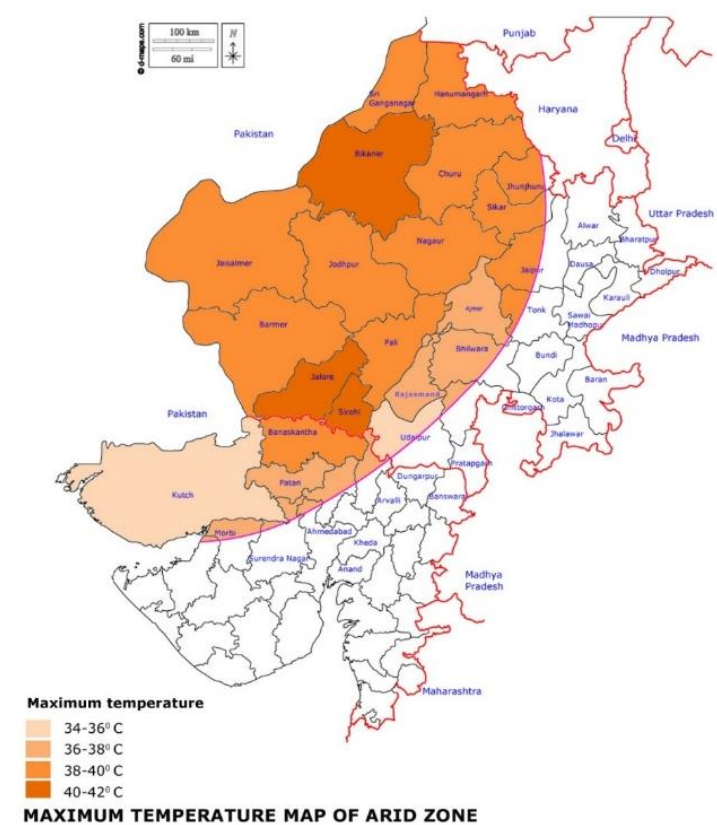

Figure 04: Minimum temperature of arid zone

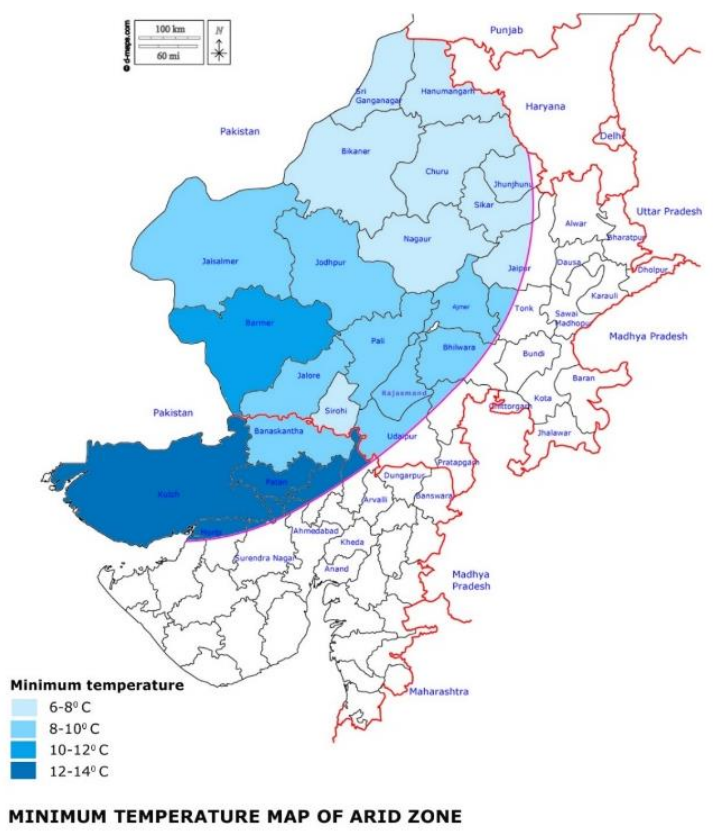

Source: en.climate-data.org

Table 02: Analysis of Annual Average Maximum and Minimum Temperature of Arid Zone

\begin{tabular}{|c|c|c|c|c|}
\hline \multirow{5}{*}{ 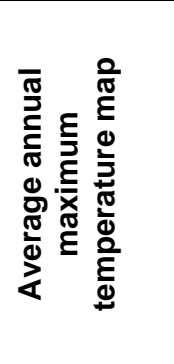 } & $\begin{array}{l}\text { Range } \\
\left(\text { in }{ }^{\circ} \mathrm{C}\right)\end{array}$ & Area of Arid Zone & $\begin{array}{l}\text { Covers in } \\
\text { percent of the } \\
\text { total arid zone }\end{array}$ & $\begin{array}{l}\text { Covered area } \\
\text { (sq.km) }\end{array}$ \\
\hline & $34-36$ & SW & 14 & 45796 \\
\hline & $36-38$ & $\begin{array}{l}\text { South and SE (Rajasmand, Bhilwara, Ajmer and } \\
\text { Patan) }\end{array}$ & 11.86 & 37946.47 \\
\hline & $38-40$ & $\begin{array}{l}\text { Central part to North and North West } \\
\text { (Banaskantha, Jodhpur, Barmer, Nagaur, Churu, } \\
\text { Pali, Sikar and Jhunjhunu) }\end{array}$ & $38-40$ & 121294.94 \\
\hline & $40-42$ & Bikaner, Jalore and Sirohi & 35.88 & 114779.64 \\
\hline \multirow{4}{*}{ 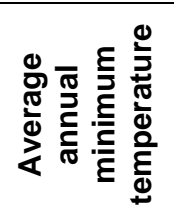 } & $6-8$ & $\begin{array}{l}\text { North (Bikaner, Nagaur, Sikar, Jaipur, Churu, Sri } \\
\text { Ganganagar) }\end{array}$ & 34.47 & 75792.48 \\
\hline & $8-10$ & $\begin{array}{l}\text { North west and Central (Rajasmand, Bhilwara, } \\
\text { Ajmer and Patan) }\end{array}$ & 20.53 & 65680.33 \\
\hline & $10-12$ & South West & 8.87 & 28387 \\
\hline & $12-14$ & Kutch, Patan, Mehsana and Sabar Kantha & 46.8 & 149957.17 \\
\hline
\end{tabular}

\section{Humidity analysis of arid zone:}

Humidity represents the moisture in the air and it is a dependent factor of evaporation, evapotranspiration, depth of water level and settlement pattern. The analysis of the humidity can be classified as follows (Fig. 5): 


\section{Figure 05: Annual Humidity of arid zone}

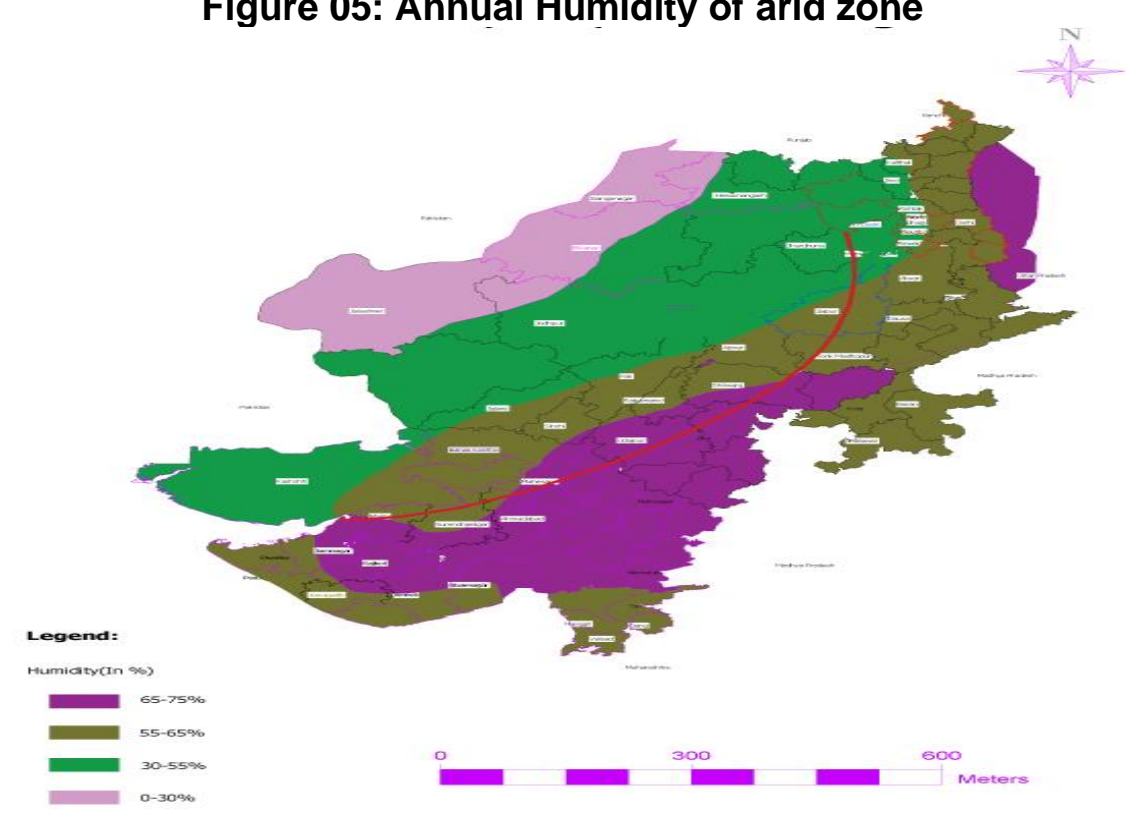

Source: India Meteorological Department

Zone 1 covers the Eastern part with variation from 65-75 percent which clearly indicates the good condition of rainfall, depth to water level, and evaporation factors. It covers 5.5 percent of the total area and occupies 17597.34 sq. km area in arid zone. Zone 2 humidity ranges from 55-65 percent. It covers almost Central part of the area at places. It is also found in chunk of patches in the Southern part of the area. It covers 21.21 percent of the total area and occupies 67855.67 sq.km area in arid zone. Zone 3 ranges from $30-55$ percent. It covers 50.05 percent of the total area and occupies 160100.32 sq. $\mathrm{km}$ area in arid zone. Zone 4 covers Western part of area where humidity varies from 0-30 percent. This area clearly indicates the absence of water bodies, low rainfall and high temperature ranges. It covers 23.22 percent of the total area and occupies 74263.65 sq. km area in arid zone.

\section{Analysis of evaporation:}

For the analysis of the evaporation was undertaken using IMD data (Fig.6) and also book of Hydrology by Prof. Subramanayam. The area like temperature, rainfall, and humidity also has been classified in the four categories as follow:

\section{Figure 06: Annual Evaporation of arid zone,}

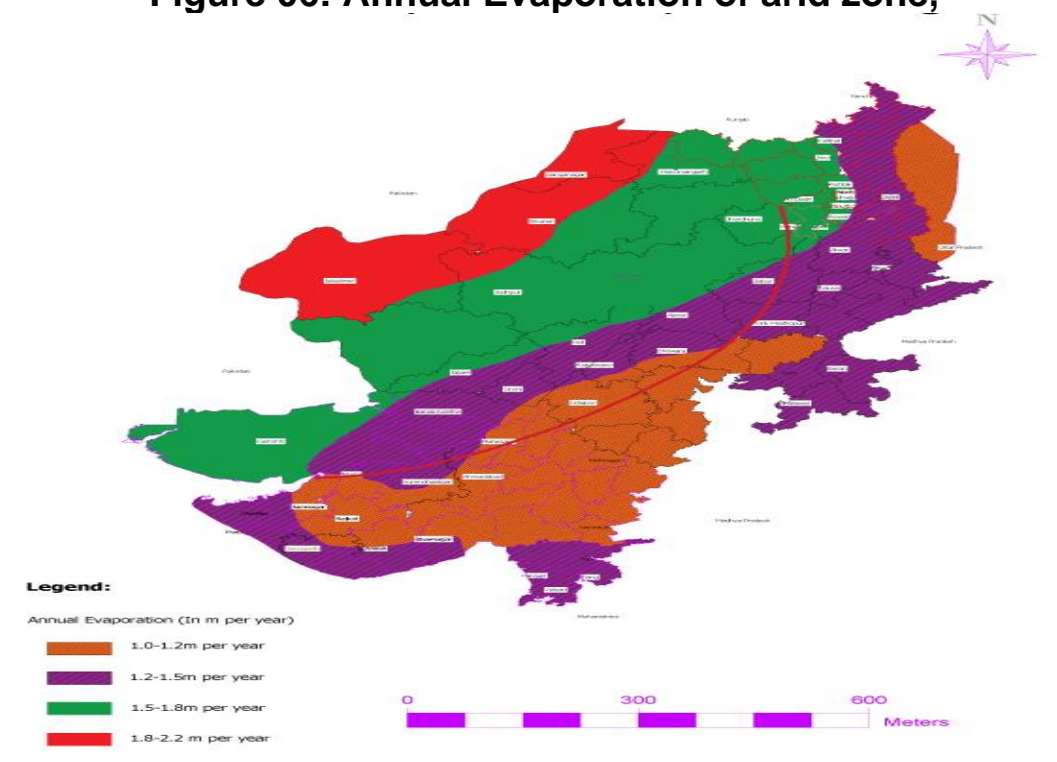

Source: IMD and Hydrology by Subramanayam 
Zone 1 occupies Eastern margin of the area where the rainfall recorded as highest and depth of water is comparatively shallow. Evaporation rate in the zone $1-1.2 \mathrm{~m}$ per year which clearly indicates that any water body in this area less than $1.2 \mathrm{~m}$ depth will be dry in the pre-monsoon season. However, the evaporation rate will be gradual as per the post-monsoon to pre-monsoons water level of the water body. Zone 2 has evaporation rate varies from 1.2-1.5m per year further indicates that any water body behind less than $1.5 \mathrm{~m}$ will not able to survive throughout the year. Zone 3 comprises of evaporation rate varies from $1.5-1.8 \mathrm{~m}$ per year indicates that any water body less than $1.8 \mathrm{~m}$ deep will not be able to survive. Zone 4 comprises of evaporation rate varies from 1.8-2.2m per year in which any water body less than $2.2 \mathrm{~m}$ will dry during the pre-monsoon period i.e. May -June.

\section{Analysis of evapo-transpiration:}

The evapo-transpiration is based upon the evaporation as well as transpiration from the vegetation cover. On the basis of evaporation and transpiration, the area may have classified in four categories (Fig.7) :

\section{Figure 07: Annual evapotranspiration of arid zone}

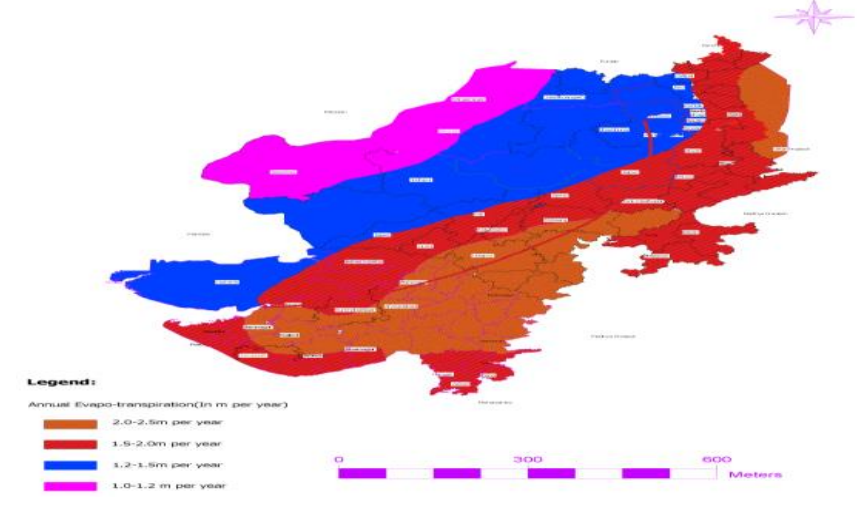

Source: IMD and Hydrology by Subramanayam

Zone 1 comprises of evapo-transpiration rate ranging from 2-2.5m/year which clearly indicate the maximum evapo-transpiration in this area is due to high density of vegetation and their foliage and canopy, shadow of the tree reduces that the direct falling of sun rays on the water body. As a result, the evapo-transpiration in this range recorded maximum because of the vegetation density as well as water bodies are found comparatively high density. Zone 2 recorded range from $1.5-2 \mathrm{~m} /$ year comes under second category because of the vegetation density and water body which is comparatively lesser than zone 1. By virtue of which the transpiration rate becomes less and evaporation also decreases due to lesser no. of water bodies as compare to zone 1. Zone 3 comprises of evapo transpiration rate ranging from $1.2-1.5 \mathrm{~m} / \mathrm{year}$ clearly indicate low to medium density of vegetation with comparatively lesser no. of water bodies. Zone 4 comprises of evapo-transpiration rate ranging from $1-1.2 \mathrm{~m} /$ year. This is the lowest evapotranspiration and evaporation in the study area. Because of varied less to nil water bodies and very few low-density vegetation.

\section{Soil Analysis}

On the basis of soil category in the area, soil is main constituent of the arid zone area. The soil represents the rock type of area because these are the local soil and the genesis of these soil is due to physical and chemical weathering of the rock. Most of the area in arid zone are covered with soil with them and thick density. However, the mineral composition of the soil depends upon the mineral composition of the rock. Because these soils are entirely different from the IndoGangetic soil. Because in the Indo-Gangetic soil, the soil changes to long transportation. As a result, the geometry of the soil and the chemical composition of the soil changes from its mother rock. However, in case of arid region, the soil is an insitu product and by virtue of which the soil inherits the geo-chemical property of the rock which may be taken care for the feasibility of the plantation scheme. The soil classification as per phi alus of the soil may be demarcated in the following map (Fig. 8) which represents the soil characterization on the basis of its grain size. The interpretation of the soil on the basis of its geo-chemical properties may be interpreted as the 
following map (Fig. 9). this soil map clearly indicates the relationship of the soil with the mother rock and represents the insitu conditions.

Figure 08: Classification of soil in arid zone

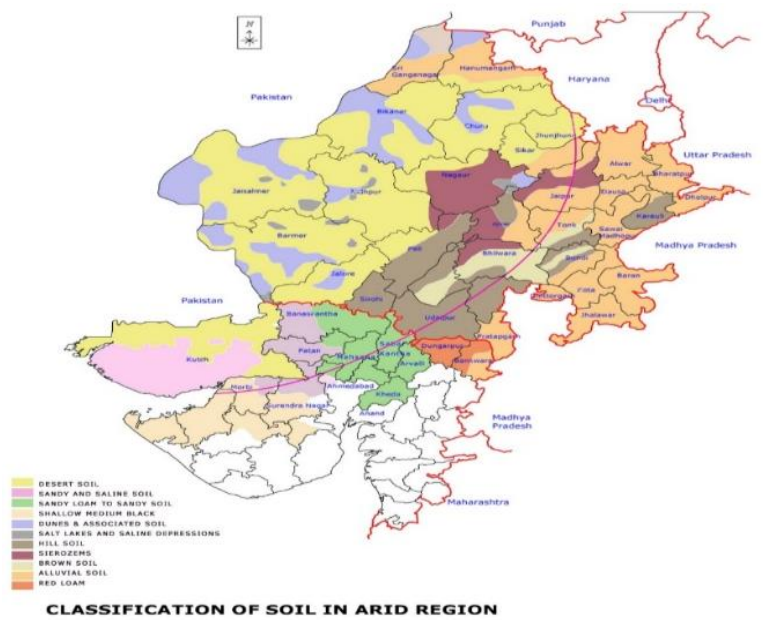

Figure 09: Type of Soil in arid zone

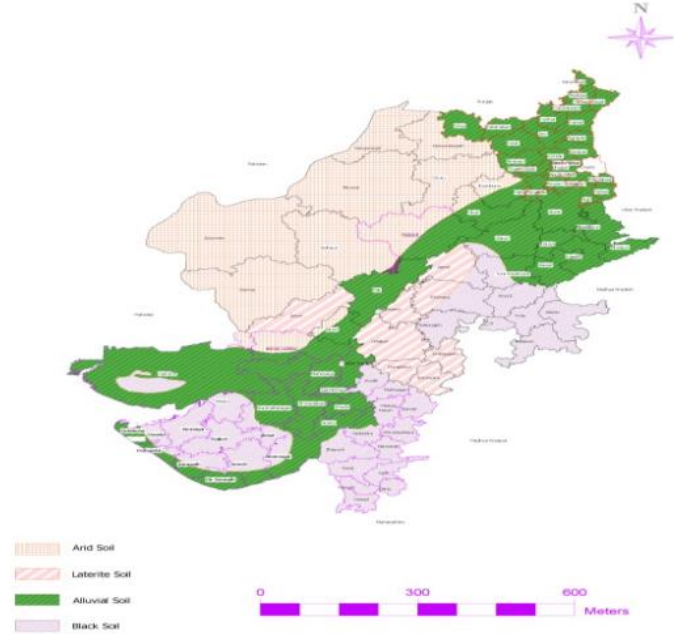

Source: Department of Agriculture U.S in 1949

Source: Department of Agriculture of Gujarat and Rajasthan

The western margin of the arid zone area represents the arid soil and the central part to North-Eastern to South Western represents the alluvial soil. The Central part and partly Eastern part represent the laterite soil which is rich in iron. The black soil has been encountered in the Eastern margin and the Southern margin of the area.

\section{Delineation of Hydrological Analysis of Arid Region}

Hydrological condition represents the impact of rain water infiltration in the sub-surface and the sub-surface area depends on the soil and rock condition. It is seen that wherever the high permeable soil encounter, the depth of water level become shallow and it also depends on rain water potential. The interpretation of the water level may be demonstrated to the various maps prepared during the following months. These are May 2019, August 2019, November 2019 and January 2020. In the month of May 2019 (Fig.10), the minimum depth water level recorded in the southern part and partly South Eastern of the area whereas the maximum depth water level recorded in Northern and Western part of the area. So it is seen from the interpretation of the depth water level for the month of May 2019, the max. depth water level was recorded in the arid zone of the area whereas the min. depth water level was recorded in the Southern and Eastern part of the area.

Figure 10: Depth to water level Pre-monsoon May 2019

\section{Figure11: Depth to water level Pre-Monsoon August 2019}
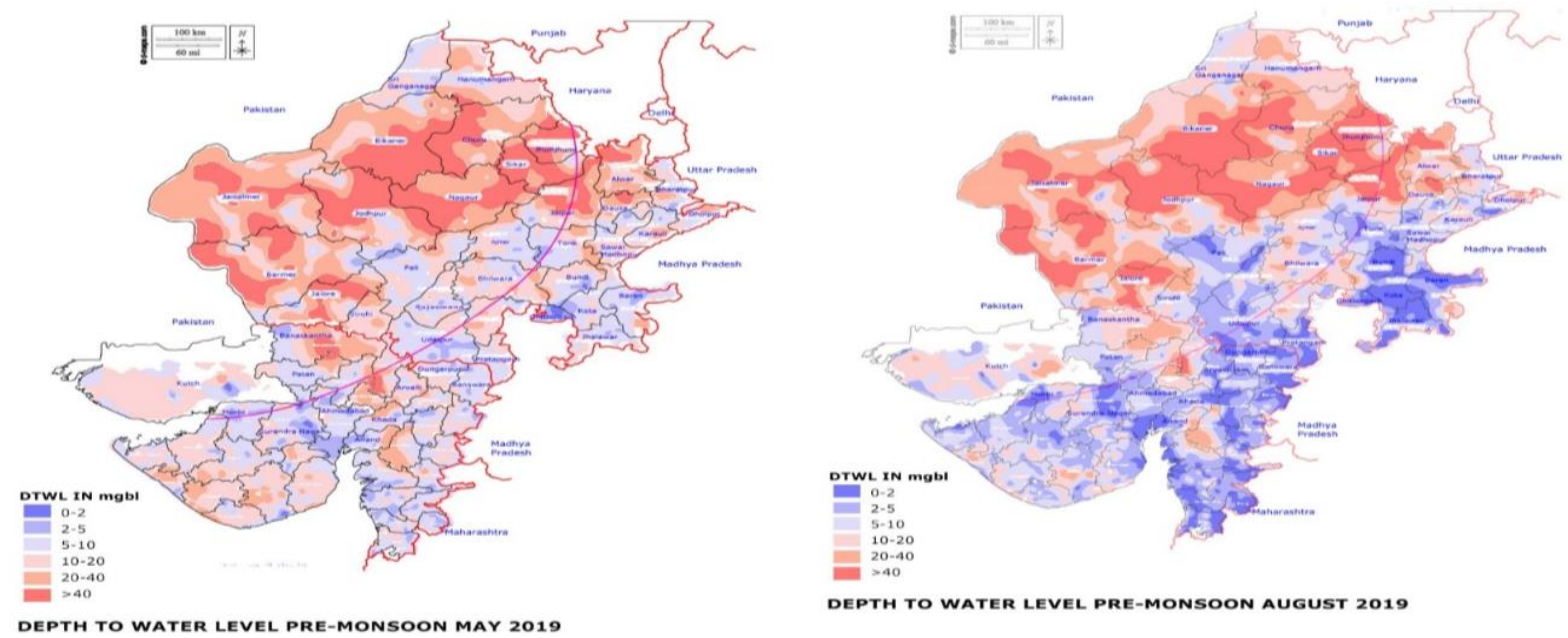

Source: Ground water year book Rajasthan 2019-20, Ground water year book Gujarat 2019-20

Source: Ground water year book Rajasthan 2019-20, Ground water year book Gujarat 2019-20 
Here in the month of August 2019 (Fig. 11), it is recorded that most of depth water level map as shallow water level was recorded in Southern and South Eastern margin whereas the maximum water level recorded in Northern and North Western margin of the area. However, the pattern follows similar to that the month of May which clearly indicate that the depth to water level condition get affected due to monsoon condition. However, the pattern doesn't change.

Figure 12: Depth to water level Post Monsoon November 2019

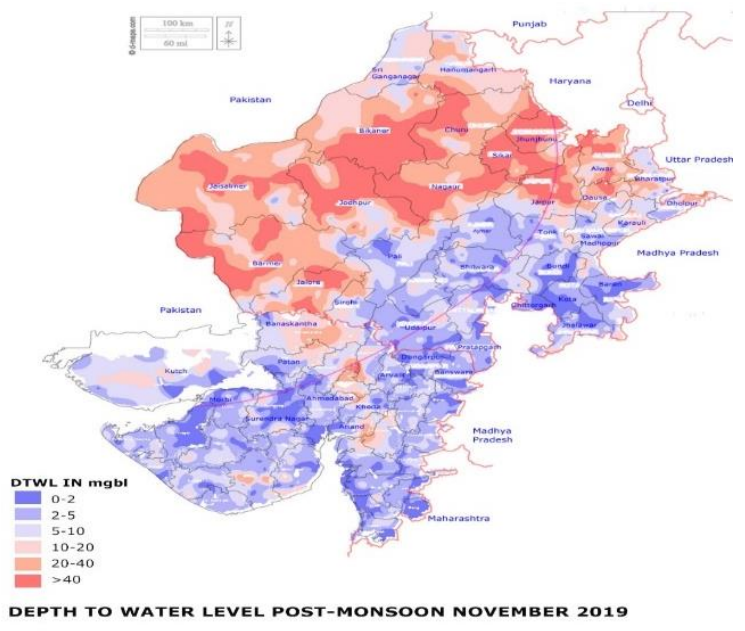

Source: Ground water year book Rajasthan 2019-20, Ground water year book Gujarat 2019-20
Figure 2: Depth to water level Pre-Monsoon January 2020

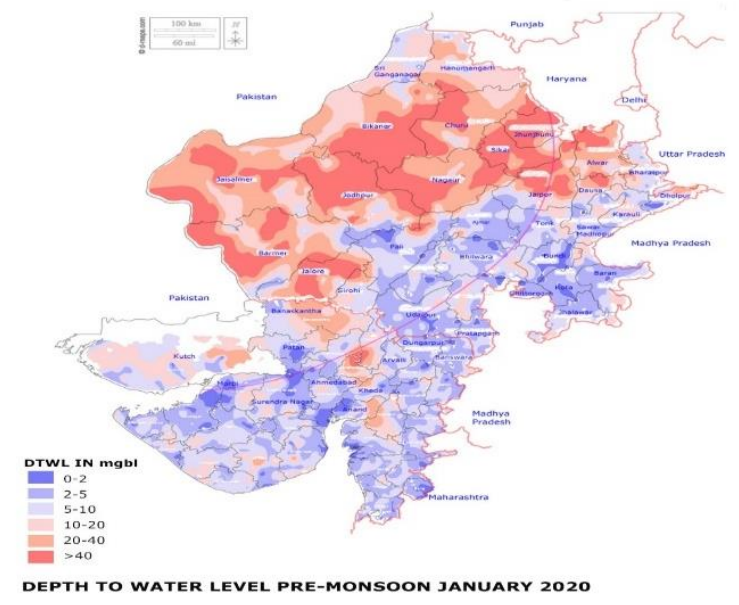

Source: Ground water year book Rajasthan 2019-20, Ground water year book Gujarat 2019-20

November 2019 map (Fig.12) represents post- monsoon map. Here also like to other maps the Southern and Eastern part brought the shallowest level whereas Northern and Western part occupies the deepest level. In the month of January 2020 (Fig.13), it is seen that declining trend of water level in the area and most of the Southern and Central part of the area requires comparatively the deepest water level condition. However, the pattern remains the same i.e. Southern and Eastern part of the area whereas in the Northern and Western margin of the area, the deepest water level was recorded.

\section{Water Level Fluctuation}

The water level fluctuation direct response of the rain water infiltration in the ground water with due consideration of the permeability of the soil and also water retention capacity. The water level fluctuation was recorded on the basis of rise and fall of the water level from pre-monsoon to postmonsoon of the region. And it is seen that the Southern and Western part of the area with Central and Eastern part and surprisingly the Northern part shows the rising trend of water level whereas the Western part and partly Central and North Eastern part shows the declining trend of water level. These conditions are very important for the development of the green campuses. (Fig.14)

Figure 14: Fluctuation of Ground Water May 2019- August 2019

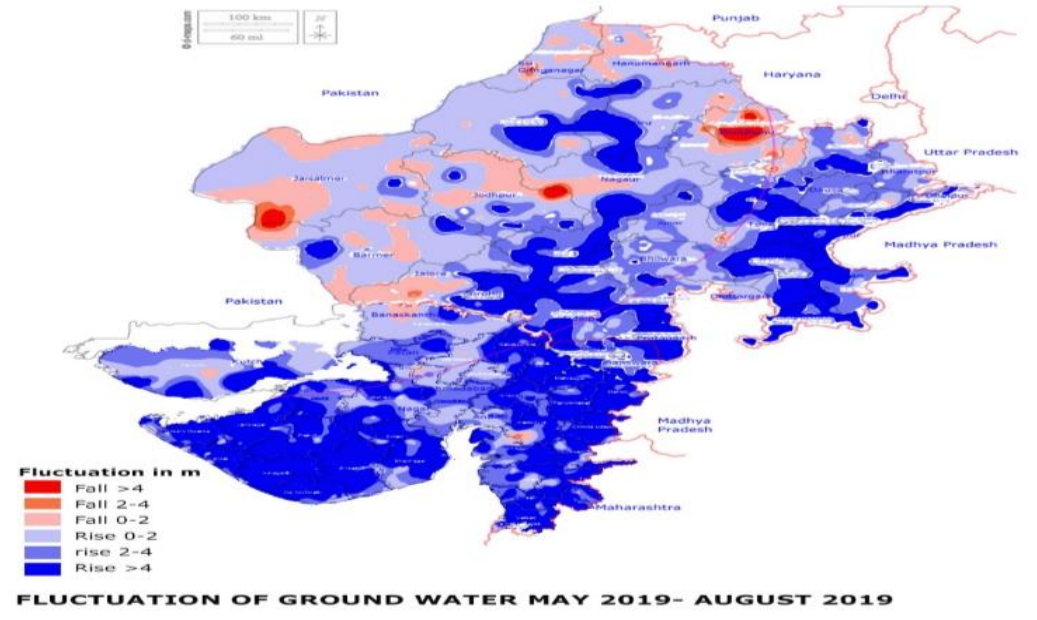

Source: Ground water year book Rajasthan 2019-20, Ground water year book Gujarat 2019-20 
The water level fluctuation in the Southern and Northern with Central and Eastern part shows the rising trend of water level whereas the Western part and partly North western part shows the declining trend of water level. (Fig.15)

Figure 15: Fluctuation of Ground Water May 2019- January 2020

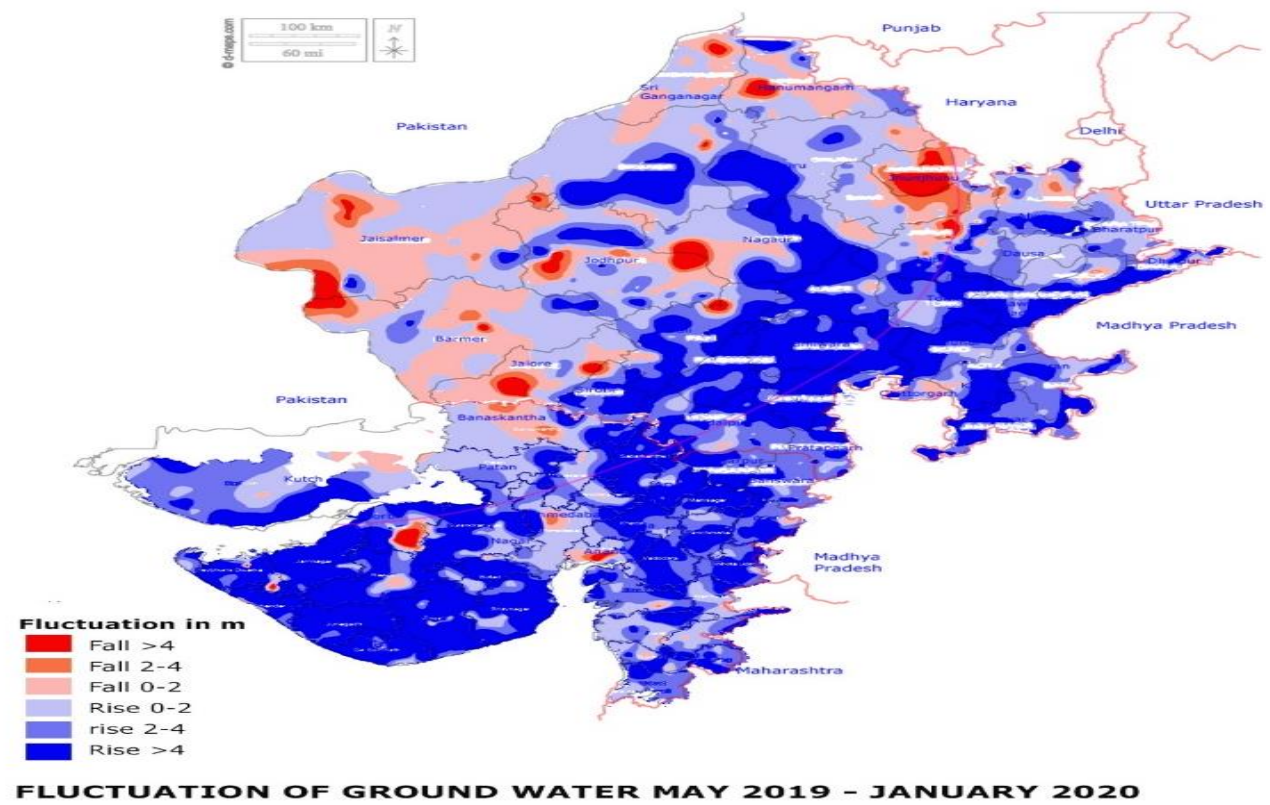

Source: Ground water year book Rajasthan 2019-20, Ground water year book Gujarat 2019-20

The water level fluctuation in the Southern, partly western and Northern with Central and Eastern part shows the rising trend of water level whereas partly Western and Northern part shows the declining trend of water level which is minor in scale. (Fig.16)

Figure 16: Fluctuation of Ground Water May 2019- November 2019,

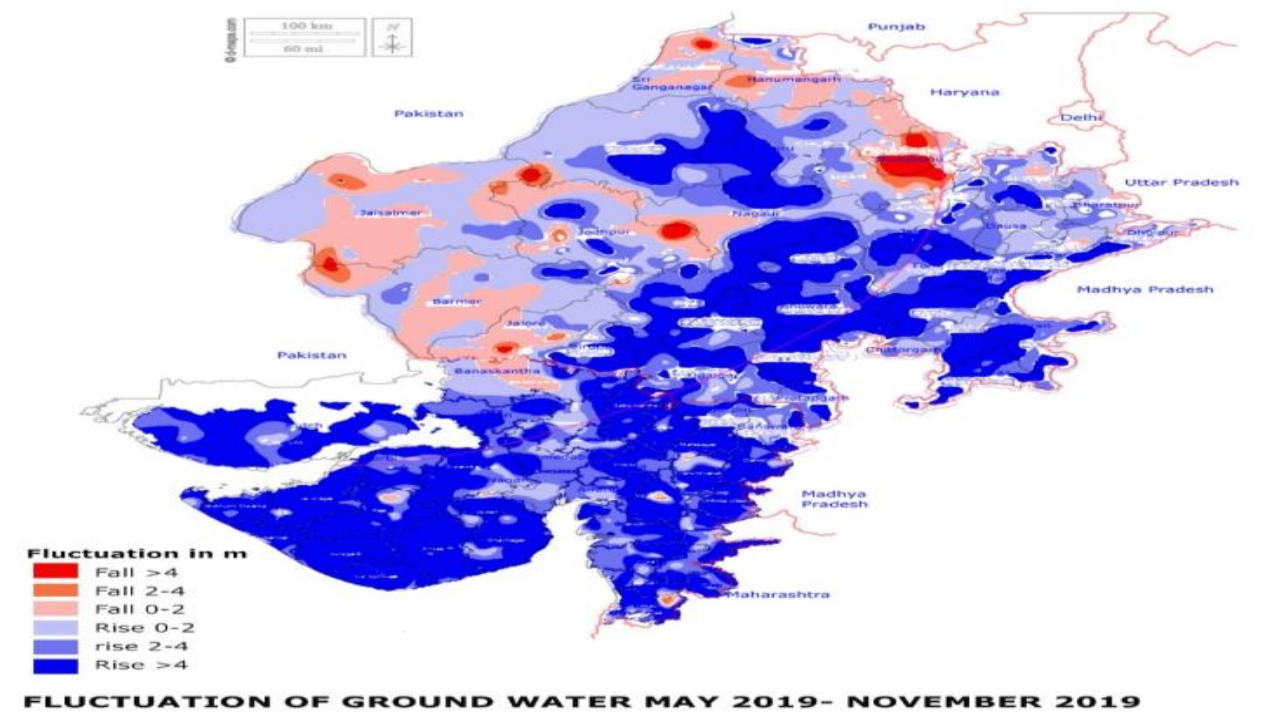

Source: Ground water year book Rajasthan 2019-20, Ground water year book Gujarat 2019-20

\section{Decadal Variation}

The map represents the decadal rise and fall from May 2009-18 (Fig.17) with the help of 10 years' data. The red colour shows the fall in water level condition and dark blue colour shows the rise in water level condition. However, the colour represent the water level rise and fall. The interpretation of the map indicates clearly the water level behavior and impact assessment on the ground water abstraction by the natural and man-made activities and also due to urbanization. It is seen that water level in May-June and January map and water level fluctuation of the subsequent month that the rich zones had been converted into low rising zone and most of them 
in the Southern and almost Southern, Western, Northern and Eastern and almost in the entire arid zone there is a drastic fall in water level condition. Surprisingly, the Western margin of the arid zone has got marginal rise of the water level. This is because of the low to very low urbanization due to climatic condition.

Figure 17: Decadal water variation of water level, Figure 18: Decadal Water variation of
water level May 2019

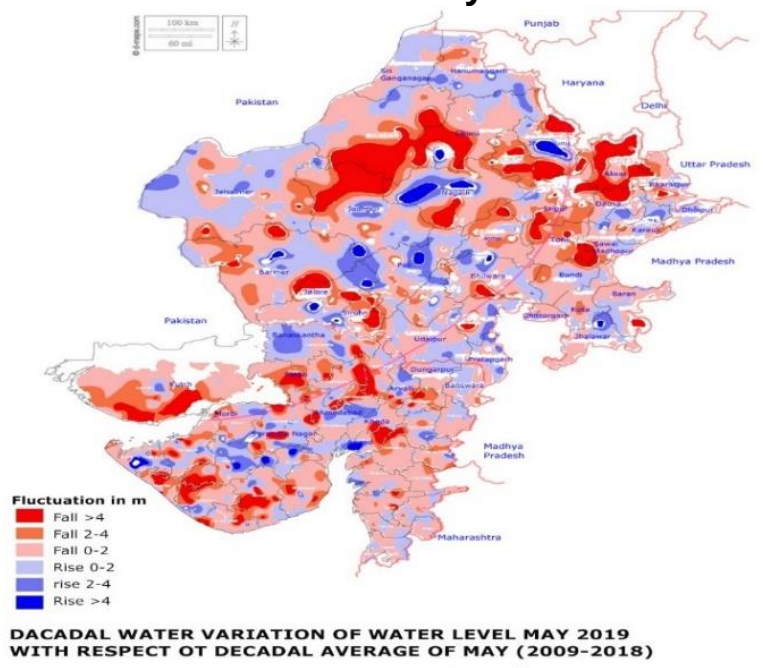

Source: Ground water year book Rajasthan 2019-20, Ground water year book Gujarat 2019-20

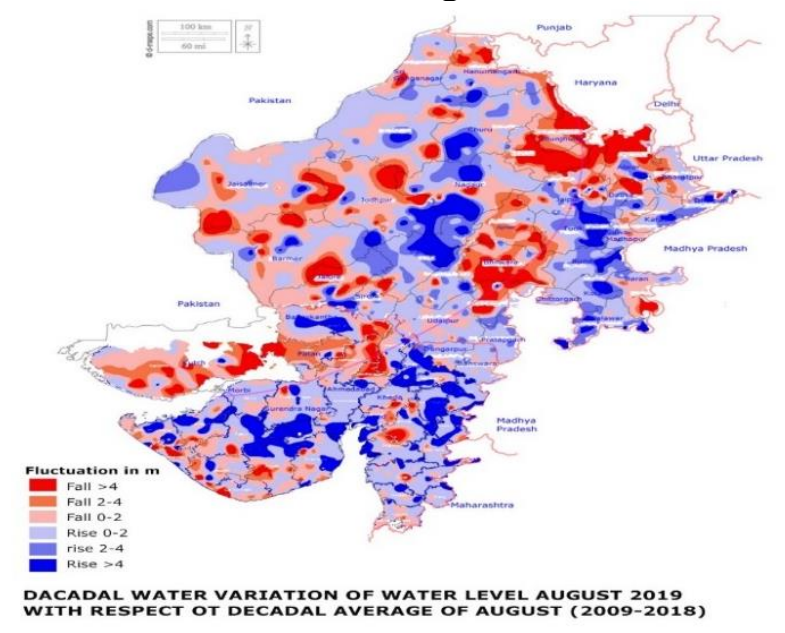

Source: Ground water year book Rajasthan 2019-20, Ground water year book Gujarat 2019-20

The interpretation of the map August 2009-18 (Fig.18) indicates clearly the water level behavior and impact assessment on the ground water abstraction by the natural and man-made activities and also due to urbanization. It is seen that rich zones had been converted into low rising zone and most of them in the Southern and almost Southern, Central, Northern zone. It is seen that water level variation in November 2009-2018 (Fig.19) has surprisingly shows the rise of water in Northern, Central and Southern and Eastern part of arid zone whereas the water is falling in Western part of arid zone. As compare to water level variation in January 2010-19 (Fig.20), it reveals that water level is rising except the western part of arid zone. Rise is scattered from south east to south-central, north western, western and west central parts of the State.

Figure 19: Decadal water variation of water level Figure 20: Decadal water variation of November 2019 water level January 2020

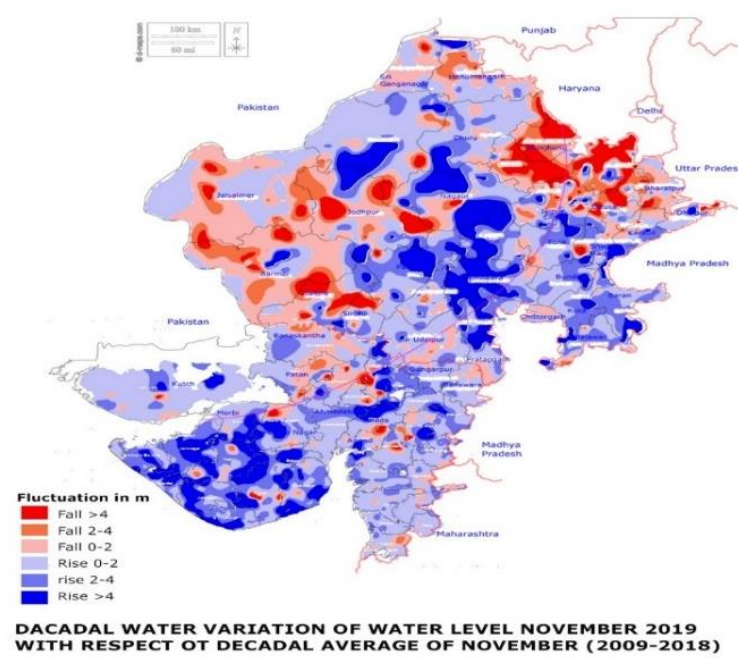

Source: Ground water year book Rajasthan 2019-20, Ground water year book Gujarat 2019-20

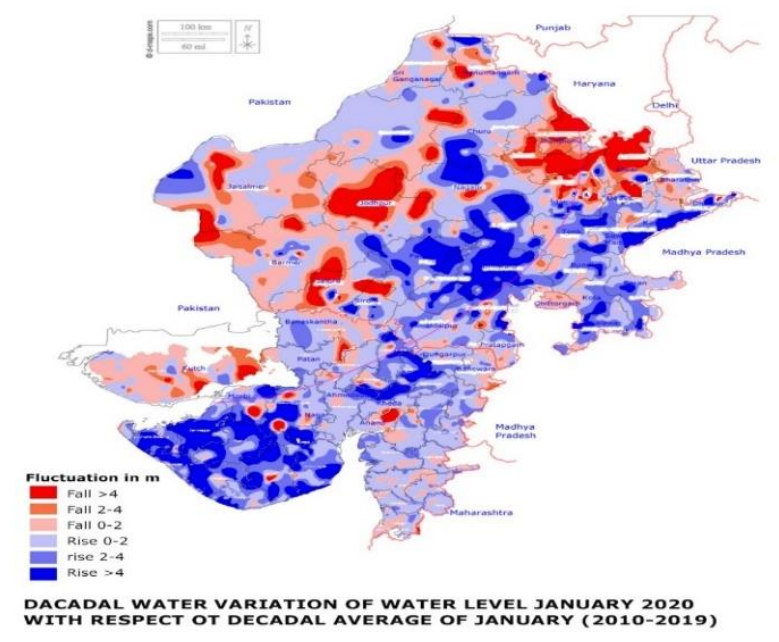

Source: Ground water year book Rajasthan 2019-20, Ground water year book Gujarat 2019-20 


\section{Interpretation Based on Parameters}

The interpretation variable is the assessment of natural green campus potential from very low potential i.e. Jaisalmer to very high potential area passing through Jaisalmer, Jodhpur, Nagaur, Sikar and Jaipur and many more sections which run from West to East. In order to assess the natural potential zone, the following criteria have been adopted:

1. Average ground water level

2. Annual average evaporation and evapo-transpiration

3. Average temperature and

4. Humidity based on the soil cover of the arid zone.

The interpretation of the curve taken as following:

1. In a very low potential area (Fig.21) i.e. Jaisalmer, humidity was recorded 15 percent and the temperature was recorded as $24^{\circ} \mathrm{C}$ i.e. average of maximum and minimum temperature whereas the average ground water level was $40 \mathrm{~m}$, annual average evaporation $2 \mathrm{~m} /$ year and evapo-transpiration $1.1 \mathrm{~m} /$ year. The dominant soil in this area is arid i.e. coarse sandy soil mix with fine to medium soil. It has been observed that low humidity and high rate of evaporation and evapo-transpiration with deep water level condition becomes worse when the local soil is coarse mix with fine dust which absorbs lot of solar radiation as a result the area converted into desert.

\section{Figure 21: Natural Green Campus Potential Assessment from west to east section in arid zone}

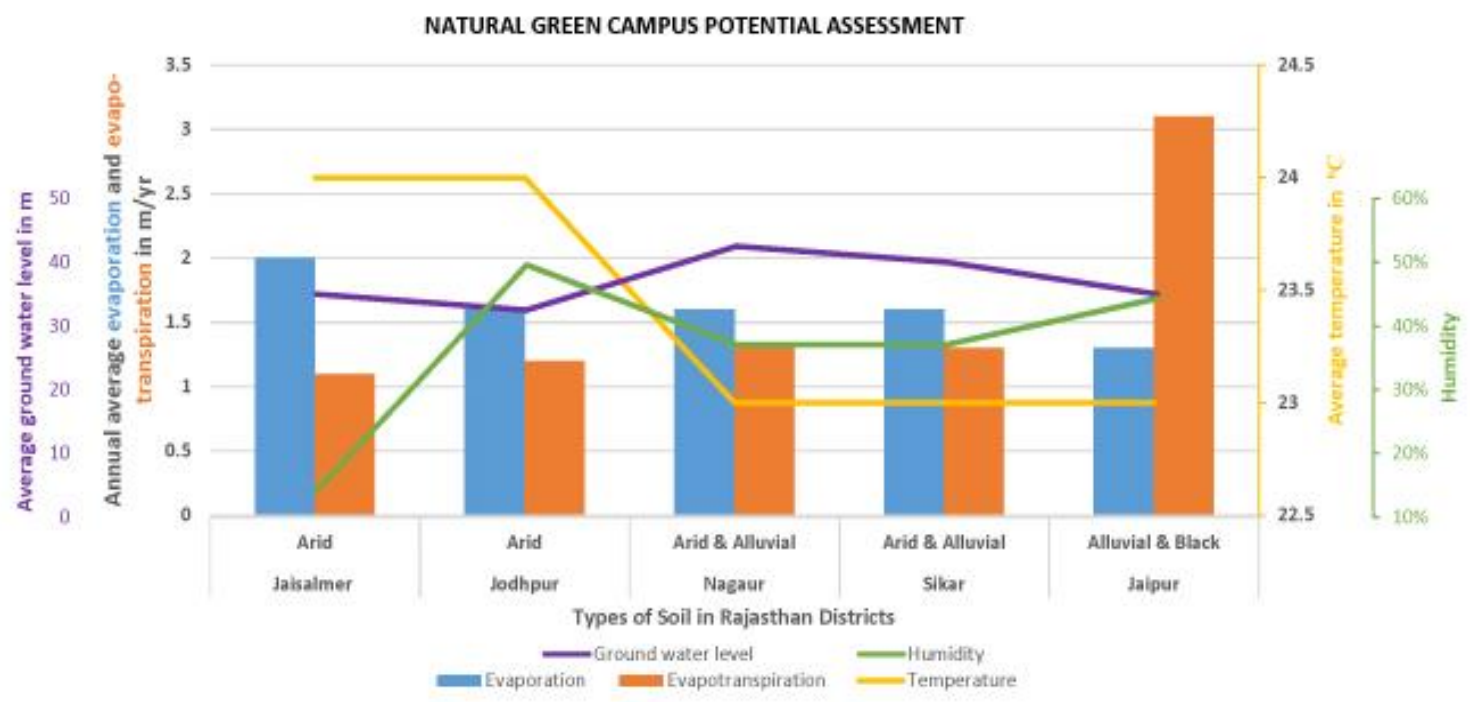

Source: Author

In Jodhpur, the humidity is high whereas the annual average evaporation and evapotranspiration rate are medium with deep water level condition makes low potential for green campus development as the local soil is coarse mix with medium sand and fine dust particle which absorbs lot of solar radiation which may converted area into desert. In Nagaur, green patches are more as compare to Jaisalmer and Jodhpur as the soil is arid and alluvial (i.e. mix of coarse, clay and loam) and evaporation, evapotranspiration, humidity, water level conditions are better. Therefore, natural green area has been encountered in better condition as compare to Jaisalmer and Jodhpur. In the hierarchy of interpretation based on parameters, Sikar is also having high potential to develop Green campus development. Jaipur has been observed as very high potential zone for Green Campus development because of soil type i.e. Alluvial and Black soil which is natural weathered rock soil and having better climatic condition.

2. The interpretation of various parameters assessment from Barmer, Jalore, Pali, Rajasmand to Bhilwara becomes better potential for Green Campus development. (Fig.22) 
Barmer has been found with high humidity i.e. 42 percent with low annual average evaporation $1.6 \mathrm{~m} /$ year and evapotranspiration $1.3 \mathrm{~m} /$ year whereas the average temperature was recorded $25^{\circ} \mathrm{C}$ with arid soil having coarse and medium sand with dust particle in this area which resulted into desert having medium potential to develop green campus development. In Jalore, the permeability of soil is very high with good fissure zone along with more iron content. Therefore, being metallic in nature, vegetation cover losses due to high permeability, deep ground water level condition i.e. $35 \mathrm{~m}$, medium temperature $25^{\circ} \mathrm{C}$, high evaporation and evapotranspiration with laterite soil. Pali has comparatively better condition because of alluvial soil having coarse sand mix with clayey and loam due to local depression in arid zone. It has good potential as it has good soil content with low evaporation and evapotranspiration, shallow ground water level as compare to Barmer and Jalore.

Figure 22: Natural Green Campus Potential Assessment from west to east section in Arid Zone

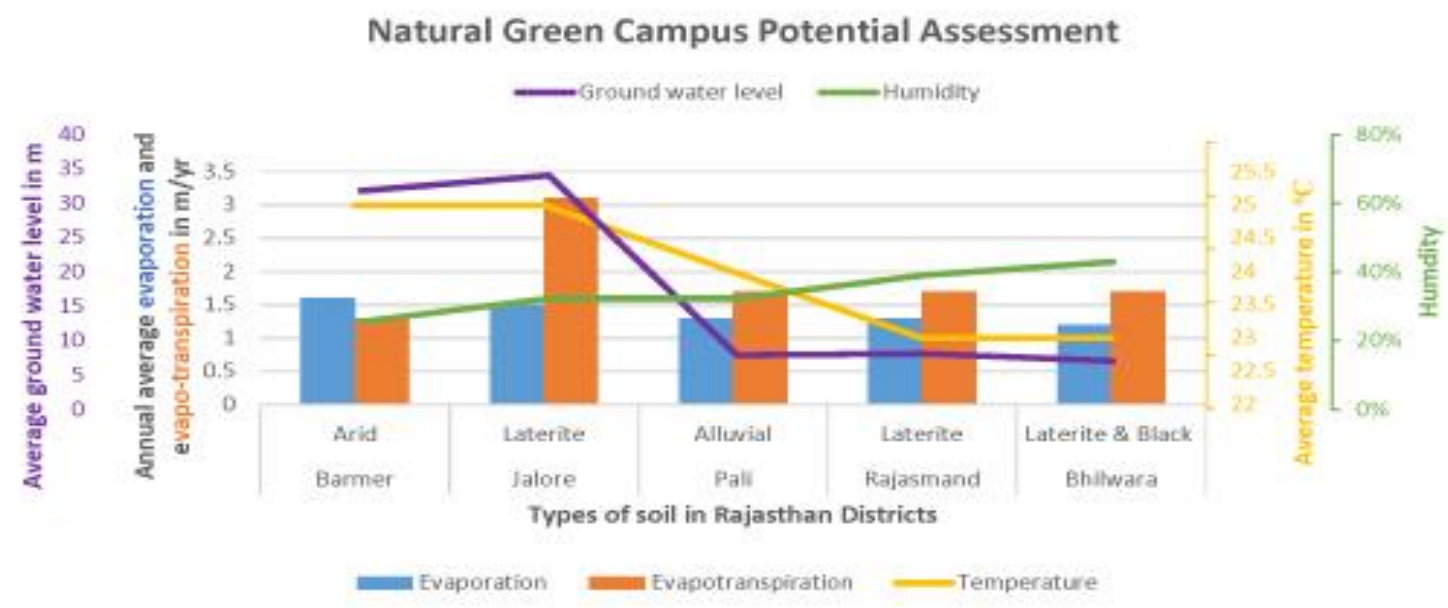

Rajasmand has shallow water level condition having laterite soil. It has potential for natural green campus development compare to Jalore as its evaporation $1.3 \mathrm{~m} /$ year and evapotranspiration $1.7 \mathrm{~m} /$ year rate are better. It has been observed that Bhilwara has high potential for green campus development shallow ground water level condition i.e., $7.1 \mathrm{~m}$, low annual average evaporation $1.2 \mathrm{~m} /$ year and evapotranspiration $1.7 \mathrm{~m} /$ year, average temperature $23^{\circ} \mathrm{C}$ with laterite and black soil (natural weathered rock soil) increase very high potential area for green campus development.

3. Kutch has saline water zone due to oceanic intrusion. Therefore, area has got low ground water level potential because of water quality and alluvial soil and has very low potential for green campus development. (Fig.23)

Figure 23: Natural Green Campus Potential Assessment from west to east section in arid zone

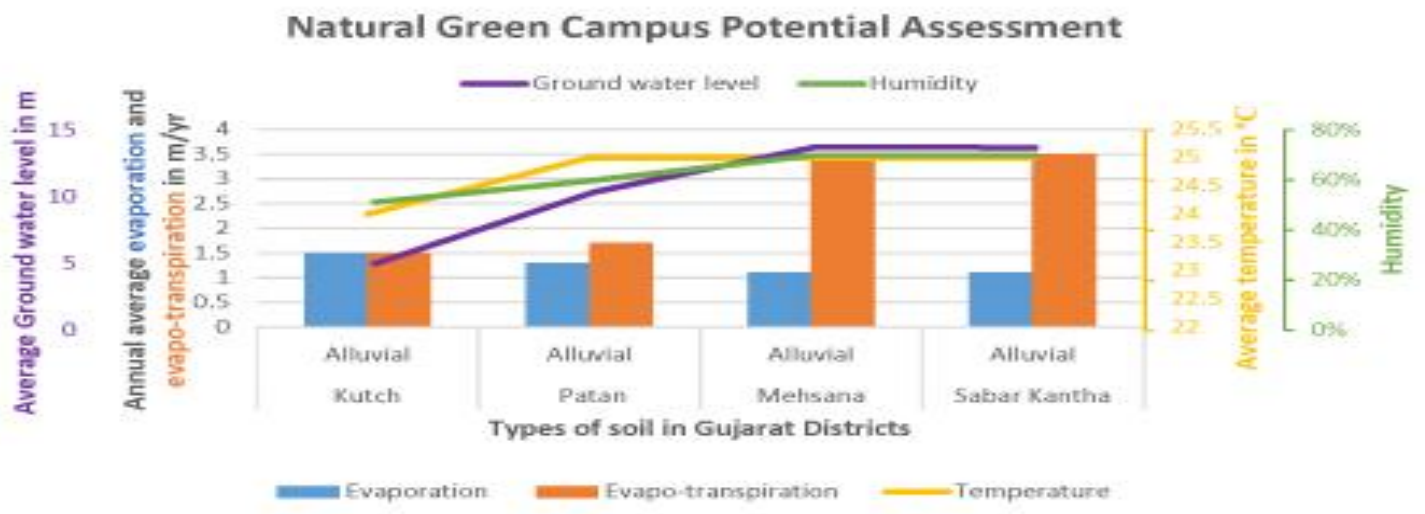

Patan has deep water ground water level and low intrusion of saline water with shallow ground water level i.e. $10.38 \mathrm{~m}$ whereas high average temperature and humidity. As compare to 
Kutch, it has low potential. Mehsana and Sabar Kantha have better water level condition and do not have any intrusion of sea water in this arid zone.

\section{Conclusion and Recommendation}

In order to develop the Green Campus within the arid zone, it has been divided into four micro zone from west to east. The basis of the classification of this zones are rainfall, temperature, humidity, evaporation and evapotranspiration and natural soil condition. It is seen that the Eastern zone has got comparatively the highest potential for the development of the green campus and the Western zone has lowest potential for further development of green campus. After the Eastern zone, another micro-level zone has been developed which has got the second category of development of Green campus followed by Central micro-zone has medium to low potential as compare to the western micro zone which has got very low potential for the development of green campus. It is also concluded that the highest potential zone has got very limited area. The second category of the micro level potential zone has got low to medium aerial extent and the third category of micro level potential zone has very vast area and finally the low potential micro-level zone in the Western part has got the lowest aerial extent.

Further, it is recommended that that water will be decisive factor in all the condition for the development of the Green Campus since at present rainfall and ground water is the only source of water. Therefore, the innovative technique like comprehensive water management plan, rain water harvesting master plan, recycling and reuse of waste water with the pace of development of the area due to urbanization which is possible to develop the Western part and Central part also for the Green Campus development and the Western and Central part of the area must adopt the conservation and development of water resources to develop the green campus for the various projects. However, the first and second category of the area which is located in Eastern and adjoining part must take care about the preservation of natural green campus so that the further deterioration should not take place.

This research also aims to develop the water body to revitalize the water bodies along with good vegetation cover with the help of innovative ideas using latest state of art.

\section{References}

1. Retrieved from BMPTC_Building Materials \& Technology Promotion Council : https://bmtpc.org/DataFiles/CMS/file/VAI2019/WIND-guj.html

2. Retrieved from d-maps.com: https://d-maps.com/pays.php?num_pay=435\&lang=en

3. Retrieved from Climate-Data.org: https://en.climate-data.org/asia/india/rajasthan/pali-24629/

4. Climate of Rajasthan. (2021). Pune: GOI, IMD, Ministry of Science.

5. Ground water year book 2019-2020. Ahmedabad: Central Ground Water Board Department of Water Resources, River Development and Ganga Rejuvenation Ministry of Jal Shakti.

6. Ground Water Year Book. Jaipur: Central Ground Water Board Department of Water Resources, River Development and Ganga Rejuvenation,Ministry of Jal Shakti. (2020).

7. Roy, B. B., Dhir, R. P., \& Kolarkar, A. S. (1978). Soil of Rajasthan Desert and their characteristics. 44 B, pp. 161-167. Indian National Science Academy.

8. Smith, T. A. (1949). Old system of Soil Classification. Retrieved from https://www. rajras.in/rajasthan/geography/soils/

9. (2015). Soil. Gujarat Ecology Commission. Department of Agriculture, Gujarat. Retrieved from http://www.gujenvis.nic.in/PDF/soil.pdf

10. Subramanya, K. (2008). Engineering Hydrology (3 ed.). Tata McGraw Hill. 